\title{
Risk of cardiac dysrhythmias in chronic spinal cord injury patients
}

\author{
D A Leaf MD MPH, ${ }^{1} \mathrm{R}$ A Bahl MD,$^{2} \mathrm{R} \mathrm{H}$ Adkins $\mathrm{PhD}^{3}$ \\ ${ }^{1}$ Center for Health Promotion and Disease Prevention, UCLA School of Medicine, Center \\ for Health Sciences, 10833 Le Conte Avenue, Los Angeles, California, 90024-1772, USA; \\ ${ }^{2}$ Division of Cardiology, School of Medicine, University of Southern California Los \\ Angeles, California, USA; ${ }^{3}$ Regional Spinal Cord Injury Care System of Southern \\ California, Rancho Los Amigos Medical Center, Downey, California, USA.
}

\begin{abstract}
The incidence of cardiac dysrhythmias is characterized in a group of 47 chronic SCI patients (greater than 30 days post injury; range 35-3605 days) with SCI lesions ranging from $\mathrm{C} 4$ to $\mathrm{L} 3$ who were referred for evaluation of a potential cardiac dysrhythmia by 24 hour Holter monitoring. Patients were grouped according to level of injury as paraplegic (T1 and below), $n=22$, or quadriplegic $(\mathrm{C} 3-\mathrm{C} 8), n=25$. No evidence of life threatening dysrhythmias was noted in either group, and no differences were evidenced in the incidence of cardiac dysrhythmias between the groups. Premature ventricular contractions (PVCs) were noted in $4 / 25$ quadripelgics, and in $1 / 22$ paraplegics, and right bundle branch block (RBBB) was noted in $1 / 25$ quadriplegics and $1 / 22$ paraplegics. A two-year chart review follow up revealed that no clinically significant cardiac dysrhythmic events occurred in these patients. These findings suggest that the risk of cardiac dysrhythmia is attenuated following the acute phases of SCI and represents a diminished concern to the clinician.
\end{abstract}

Keywords: cardiac dysrhythmia; spinal cord injury.

\section{Introduction}

The spinal cord injured represent a population of over 250,000 United States citizens at a growing rate of 7,000-10,000 new spinal cord injury (SCI) victims each year. ${ }^{1-6} \mathrm{Al}-$ though the lifespan of SCI patients was dismally brief in the past, in recent years with improved management of the leading causes of acute mortality in this population (genitourinary sepsis and renal failure) the SCI population is experiencing a longer life expectancy. ${ }^{7}$

Issues regarding medical care concerns for the chronic SCI patient are disproportionately less characterized than are the variety of potentially life threatening complications arising in the acute SCI setting. ${ }^{8}$ From the cardiological perspective, acute SCI patients experience an alteration in cardiac and hemodynamic status related to injury induced autonomic nervous system dysfunction. ${ }^{9}$

Cardiac dysrhythmias are a particular concern in the acute phases of SCI (less than
14 days of injury). Ubiquitous episodes of persistent bradycardia in patients with cervical SCI have been demonstrated but are rarely noted in SCI patients experiencing thoracolumbar levels of injury. ${ }^{9}$ Severe episodes of bradycardia and tachyarrhythmias may account for the clinically important incidence of primary cardiac arrest occurring in the severe cervical injury groups (ie complete lesion motor function) compared with other SCI groups. Whether cardiac dysrhythmias noted acutely after SCI remain a persistent concern during the chronic phase of SCI has not been established. The purpose of this study is to characterize the findings of 24 hour Holter monitoring in a population of chronic SCI patients believed to be at high risk for cardiac dysrhythmias, and clinical outcome.

\section{Methods}

Subjects included in this study are a group of 
SCI patients regularly cared for at Rancho Los Amigos Medical Center, Downey, California. This setting provides the opportunity for long term follow up of these patients. Twenty four hour Holter monitor reports were reviewed from 59 consecutive SCI patients over a 5-year period (1982-1987). These Holter monitoring procedures were done in the course of the usual patient care for clinical findings suggesting the presence of a potential cardiac dysrhythmia, ie palpitations or lightheadedness. Twelve patients were excluded because monitoring was performed within 30 days or less of injury. The determination of the level of SCI was based on a comprehensive standardized manually performed physical examination. ${ }^{10}$ The SCI patients had no documented personal history of coronary artery disease, hypertension, diabetes mellitus, nor were they receiving medications which influence the autonomic nervous system or cardiac function.

Data gathering was accomplished by chart audit of medical records obtained from those who received 24 hour Holter monitoring. The charts of all patients included in this study were reviewed for a period of 2 years or longer following the Holter monitoring procedure. The complete 24 hour Holter monitor report and accompanying activity $\log$ for each identified subject was reviewed by a cardiologist. The 24 hour Holter monitoring procedure was obtained using a Marquette $8000 \mathrm{~T}$ Holter System with a built in computerized system (Marquette Electric Inc, $8200 \mathrm{~W}$ Towel Ave, Milwaukee, Wisconsin 53223). This technique generated a computer printout providing the low (minimum 24 hour heart rate value by Holter monitor) and high (maximum 24 hour heart rate value by Holter monitor) heart rate values, evidence of right and left bundle branch conduction blocks, atrial and ventricular dysrhythmias (including a 24 hour count of total premature ventricular contractions (PVC)), and ST-T wave segment changes which occurred during the 24 hour monitoring period. The results of the 24 hour Holter monitoring were checked and interpreted by a cardiologist with an accompanying 24 hour activity $\log$ that was provided by each patient.

\section{Data analysis}

Dysrhythmic events were considered to be present if more than 240 premature ventricular contractions occurred in a 24 hour period (more than 10 per hour) or atrioventricular conduction block was noted by the 24 hour Holter monitoring procedure. Data gathered from the chart audit were manually entered into a Compaq 286 personal computer and analyzed using a statistical package (SPSS $/ \mathrm{PC}+{ }^{\mathrm{TM}}$ ). SCI patients were grouped according to level of SCI as paraplegic ( $\mathrm{T} 1$ and below) or quadriplegic (C3-C8). Analysis of the data included descriptive characterization of the low and high cardiac rate levels for both SCI groups. Fischer's exact test was used to test for differences in dysrhythmia prevalence between the two SCI groups.

\section{Results}

Table I summarizes the descriptive characterization of these subjects which included 25 paraplegic ( 19 men, 6 women), and 22 quadriplegic (18 men, 4 women). The mean age for the paraplegic group was $42.0 \pm 18.8$ years and for the quadriplegic group $39.0 \pm 16.7$ years

The number of dysrhythmic events for the 24 hour period of monitoring included a total of five (4 PVC, $1 \mathrm{RBBB}$ ) in the quadriplegic group, and two (1 PVC, 1 $\mathrm{RBBB}$ ) in the paraplegic group. The Fisher's exact test revealed that no differences were present between the incidence of cardiac dysrhythmia in the paraplegic and in the quadriplegic groups $\left(X^{2}=0.0322\right)$.

Based on chart review for a follow up period of over a minimum of 2 years (range 24-60 months following Holter monitoring), only one SCI patient received a medication to treat a cardiac dysrhythmia. During the period of follow up, no incidence of cardiac dysrhythmia was reported in the medical records of either of the SCI groups.

\section{Discussion}

The growing number of patients with chronic SCI are an important population for the practitioner. ${ }^{1-7}$ Although cardiac dysrhythmias represent a particular clinical 
Table I Descriptive characterization of subjects separated by group (quadriplegic and paraplegic)

\begin{tabular}{|c|c|c|c|c|c|c|}
\hline $\begin{array}{l}\text { Age } \\
\text { (yrs) }\end{array}$ & Sex & Level of injury & $\begin{array}{c}\text { DPI } \\
\text { (days) }\end{array}$ & Low & High & Dysrhythmia \\
\hline \multicolumn{7}{|c|}{ Quadriplegic $(n=25)$} \\
\hline 21 & $M$ & $\mathrm{C}-8$ & 77 & 42 & 110 & - \\
\hline 21 & M & $\mathrm{C}-5$ & 35 & 57 & 125 & - \\
\hline 15 & $\mathrm{M}$ & $C-6$ & 39 & 36 & 78 & - \\
\hline 19 & M & $\mathrm{C}-4$ & 53 & 52 & 120 & - \\
\hline 67 & $\mathrm{~F}$ & $C-4$ & 64 & 55 & 110 & - \\
\hline 43 & M & $C-5$ & 1485 & 58 & 90 & - \\
\hline 33 & $\mathrm{~F}$ & $\mathrm{C}-5$ & 107 & 78 & 100 & - \\
\hline 34 & M & $C-6$ & 108 & 46 & 110 & - \\
\hline 49 & $\mathrm{M}$ & $\mathrm{C}-4$ & 122 & 80 & 110 & PVC \\
\hline 25 & M & $\mathrm{C}-5$ & 125 & 62 & 84 & - \\
\hline 53 & $\mathrm{~F}$ & $\mathrm{C}-4$ & 179 & 45 & 120 & RBBB \\
\hline 38 & M & $\mathrm{C}-4$ & 204 & 46 & 130 & - \\
\hline 20 & M & $C-4$ & 232 & 61 & 98 & - \\
\hline 47 & M & $\mathrm{C}-4$ & 262 & 41 & 75 & PVC \\
\hline 44 & $\mathrm{~F}$ & $\mathrm{C}-4$ & 337 & 40 & 68 & - \\
\hline 80 & $\mathrm{~F}$ & $C-4$ & 122 & 52 & 84 & - \\
\hline 56 & $\mathrm{M}$ & $C-6$ & 375 & 55 & 110 & - \\
\hline 38 & M & $C-4$ & 204 & 47 & 94 & - \\
\hline 59 & $\mathrm{~F}$ & $C-6$ & 572 & 48 & 72 & - \\
\hline 30 & M & $C-4$ & 635 & 70 & 110 & - \\
\hline 44 & M & $C-7$ & 772 & 74 & 70 & PVC \\
\hline 43 & M & $C-6$ & 82 & 58 & 70 & - \\
\hline 23 & M & $C-6$ & 2082 & 37 & 84 & - \\
\hline 35 & M & $C-4$ & 3605 & 62 & 108 & - \\
\hline 37 & $\mathrm{M}$ & $\mathrm{C}-7$ & 3546 & 56 & 105 & PVC \\
\hline Mean \pm SD & 42.0 & & & & $54.3 \pm 12.2$ & $99.0 \pm 18.0$ \\
\hline \multicolumn{7}{|c|}{ Paraplegic $(n=22)$} \\
\hline 46 & $\mathrm{~F}$ & $\mathrm{~T}-3$ & 7106 & 84 & 140 & - \\
\hline 59 & $\mathrm{~F}$ & $\mathrm{~T}-8$ & 35 & 74 & 180 & RBBB \\
\hline 33 & $\mathrm{M}$ & $\mathrm{T}-1$ & 2925 & 65 & 110 & - \\
\hline 26 & M & $\mathrm{T}-10$ & 38 & 75 & 140 & - \\
\hline 82 & M & $\mathrm{L}-3$ & 38 & 80 & 130 & - \\
\hline 61 & $\mathrm{~F}$ & $\mathrm{~T}-3$ & 64 & 80 & 100 & - \\
\hline 61 & M & $\mathrm{T}-11$ & 38 & 52 & 125 & - \\
\hline 32 & $\mathrm{M}$ & $\mathrm{L}-1$ & 64 & 80 & 135 & PVC \\
\hline 32 & M & $\mathrm{T}-12$ & 102 & 85 & 150 & - \\
\hline 61 & $\mathrm{~F}$ & $\mathrm{~T}-3$ & 40 & 80 & 120 & - \\
\hline 25 & $\mathrm{M}$ & $\mathrm{L}-1$ & 161 & 60 & 165 & - \\
\hline 28 & M & $\mathrm{T}-8$ & 223 & 76 & 112 & - \\
\hline 28 & M & $\mathrm{L}-2$ & 365 & 72 & 125 & - \\
\hline 19 & $\mathrm{M}$ & $\mathrm{T}-10$ & 142 & 80 & 160 & - \\
\hline 45 & $\mathrm{M}$ & $\mathrm{T}-5$ & 4646 & 76 & 132 & - \\
\hline 32 & M & T12 & 102 & 83 & 150 & - \\
\hline 71 & M & $\mathrm{T}-12$ & 3528 & 64 & 110 & - \\
\hline 24 & M & $\mathrm{T}-9$ & 603 & 88 & 140 & - \\
\hline 70 & M & $\mathrm{T}-4$ & 1432 & 65 & 113 & - \\
\hline 23 & $\mathrm{M}$ & $\mathrm{T}-6$ & 1864 & 40 & 150 & - \\
\hline 27 & $\mathrm{M}$ & $\mathrm{T}-10$ & 2426 & 51 & 125 & - \\
\hline 38 & $\mathrm{M}$ & $\mathrm{L}-3$ & 2437 & 60 & 100 & - \\
\hline Mean \pm SD & 38.6 & & & & $71.4 \pm 12.7$ & $132.4 \pm 21.2$ \\
\hline
\end{tabular}

Low $=$ lowest recorded heart rate in beats/minute by 24 hour Holter. High $=$ highest recorded heart rate in beats/minute by 24 hour Holter. Dysrhythmia code: $\mathrm{PVC}=$ premature ventricular contraction. RBBB = right bundle branch block. 
concern during acute phases of $\mathrm{SCI},{ }^{9}$ whether this remains a significant issue in the later phases of SCI recovery is uncertain. This characterization of a group of SCI patients who were given a 24 hour Holter monitor test as a result of clinician concerns for cardiac dysrhythmias with associated clinical sequelae well after the acute phase of SCI shows no evidence of increased risk.

Certain limitations are inherent in any retrospective analysis. Unfortunately, their is no readily available potential control group for comparison. The presence of coronary artery disease has an acknowledged contribution to clinical episodes of cardiac dysrhythmia and sudden cardiac death in the general population. Because the SCI patients in this study are younger than are patients who are at high risk for coronary artery disease, SCI patients are generally viewed as being of low CAD risk. However, the sedentary lifestyle inherent in SCI patients could promote increased CAD risk. ${ }^{11}$

As described in the review by Lehmann et $a l^{9} \mathrm{SCI}$ results in a predisposition to cardiac dysrhymias. Episodes of bradycardia in quadriplegic SCI patient are explained by the loss of cervical sympathetic influences causing cardiac excitation. These arise from the preganglionic fibers of the first through fourth thoracolumbar levels. The loss of the cardiotropic effect of cervical sympathetic nerve fibers allows the vagus nerve mediated influences in parasympathetic function which arise from the medulla oblongata to dominate and thus slow cardiac rate. Our findings of increased levels of high heart rate noted in the thoracolumbar SCI (para- plegic) group compared with the cervical SCI group are consistent with this pathophysiologic interpretation and mirror the findings noted during acute phases of SCI. ${ }^{9}$

Despite the theoretical basis for increased incidence of cardiac dysrhythmia in the SCI population, this did not appear to be clinically significant. Furthermore, clinical follow up of the SCI population in this study was unable to demonstrate the presence of any clinical events associated with cardiac dysrhythmia in this population for a 2-year follow up period after Holter monitoring.

\section{Conclusions}

Although the acute phase of SCI has been associated with an increased risk for cardiac dysrhythmias, our findings involving chronic SCI patients without evidence of apparent coronary artery disease indicate that the prevalence of cardiac dysrhythmias is low. In addition, we were unable to document any clinical events related to the occurrence of cardiac dysrhythmias during follow up of the chronic SCI group. These findings indicate that the concern of cardiac dysrhythmias in the chronic SCI patient without evidence of underlying coronary artery disease is probably not relevant to the practitioner compared with the acute phase SCI patients.

\section{Acknowledgement}

This study was supported in part by the National Institute for Disability and Rehabilitation Grant No G008535134.

\section{References}

1 Bracken MB, Freeman DH Jr, Hallebrand K (1981) Incidence of acute traumatic hospitalized SCI in the U.S., 1970-1977. Am J Epidemiol 113: 615-622.

2 DeVivo MJ, Fine PR, Maetz HM, Stover SK (1980) Prevalence of spinal cord injury: A reestimation employing life table techniques. Arch Neurol 32: 707-708.

3 Ergas Z (1985) Spinal cord injury in the United States: A statistical update. Cent Nerv Syst Trauma: 3: 57-85.

4 Kraus JF, Franti CE, Riggins RS, Richards D, Borhani NO. (1975) Incidence of traumatic cord lesions. J Chron Dis 28: 471-492.

5 McVey JA (1983) The Incidence and Prevalence of Spinal Cord Injury. Paralyzed Veterans of America, New York.

6 Young J, Burns P, Bowen AM, McCutchen R (1982) Spinal Cord Injury Statistics. Experience of the Regional Spinal Cord Injury Systems. Good Samaritan Medical Center, Atlanta. 
7 Geisler WO, Jousse AT, Wynne-Jones M, Breithaupt D (1983) Survival in traumatic spinal cord injury. Paraplegia 21: 364-373.

8 Luce JM (1985) Medical management of spinal cord injury. Crit Care Med 13(2): 126-131.

9 Lehmann KG, Lone JG, Piepmeier JM, Batsford WP (1987) Cardiovascular abnormalities accompanying acute spinal cord injury in humans: Incidence, time course, and severity. J Am Coll Cardiol 10: 46-52.

10 American Spinal Injury Association (1982) Standards for Neurological Classification of Spinal Injury Patients. ASIA, Chicago.

11 Leaf DA, Adkins RH, Greenwood J, Bahl RA (1990) Maximal aerobic work capacity and theoretical implications for longevity revisited in spinal cord injury patients. Ann Sports Med 5: 133-137. 